\author{
Military Technical College \\ Kobry El-Kobbah, \\ Cairo, Egypt.
}

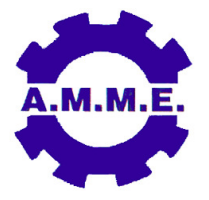

\title{
A MULTISCALE-BASED MODEL FOR COMPOSITE MATERIALS WITH EMBEDDED PZT FILAMENTS FOR ENERGY HARVESTING
}

\author{
A. E. El-Etriby ${ }^{1}$, M. E. Abdel-Meguid ${ }^{1}$, T. M. Hatem ${ }^{1}$ and Y. A. Bahei-El-Din ${ }^{1}$
}

\begin{abstract}
This current study focuses on utilizing Composite Materials with Embedded PZT Filaments for Energy Harvesting. It represents a multi-scale approach to model embedded PZT filaments in polymer based composite material. The work presented models multifunctional composite materials and structures on multiscales considering piezoelectric response to mechanical loads for the reinforcement of unidirectional composites, which are used to construct laminates of a general layup; both membrane and bending vibrational loads are considered.
\end{abstract}

The solution for the local fields is determined in terms of a transformation field analysis scheme in which the local stresses or strains, which are cannot be removed by mechanical unloading are treated as eigen fields applied in an otherwise elastic medium. In the current application, the latter represents an aggregate of unidirectional plies and their phases. Both two phase models such as the MoriTanaka model and periodic array models are employed. The solution for the overall response is determined in terms of refined plates theory using Carrera unified formulation. The overall electro-mechanical properties used are obtained from the transformation field analysis conducted earlier.

The proposed modeling strategy is applied to fibrous laminates subjected to mechanical loads. These results were then verified experimentally by using piezoelectric ceramic composites. These smart structures will be an important component in future designs of energy harvesting and multi-functional devoices to increase efficiency and recover energy.

${ }^{1}$ Center for Advanced Materials, the British University in Egypt, El-Shorouk City, Egypt. 